\title{
Codes, models and reality: reductionism vs. holism in a review of microzonation studies in the Umbria-Marche region
}

\author{
Marco Mucciarelli \\ Dipartimento di Strutture, Geotecnica e Geologia Applicata, Università della Basilicata, Potenza, Italy
}

\begin{abstract}
In the 10 years since the Umbria-Marche earthquake, several microzonation studies were carried out in the two regions. In the immediate aftermath of the event, the focus was on the epicentral area and toward emergency intervention and reconstruction plans. In the following years, regional and national projects aimed to transfer the lessons learned to other towns. Usually, those two kinds of microzonation studies are referred to as «simplified» and «detailed». The difference is more subtle, and leads to the question of whether a microzonation study can be tackled following a reductionist approach, i.e. leaving different experts taking care of a limited subject (geology, geophysics, seismology, geotechnics, structural engineering). The impression looking back at 10 years of studies is that a holistic approach would be more appropriate to describe a system (structure-soil-bedrock) that is non-linear, inhomogeneous, and presenting feedback among its components. A second problem that emerges is the link with codes and practitioners. During the past 10 years the seismic code has been changed and a new version is on arrival. The last proposed version of the code is based on a parameter (Vs30) that is discussed in the same country where it was first adopted, and introduces a parameter (acclivity) that appears to be a secondor third order problem with respect to others that are completely disregarded (e.g., 2-d site effects). A possible explanation for this mismatch between codes, models and reality is that our knowledge of distribution and amplitude of site effects is biased by selective under-sampling. Being driven by damage, and paying less attention to a uniform distribution of studied sites and situations, we act like a drunk man looking of his lost keys under a street lamp, not because he is sure that he lost them there, but because the light is there.
\end{abstract}

Key words Microzonation, Umbria-Marche earthquake, seismic codes

\section{Introduction}

The working hypothesis behind microzonation studies is that we can study a limited number of ideal situations prior to an earthquake occurrence to forecast the areas where the damage will be increased by amplification of seismic

Mailing address: Dr. Marco Mucciarelli, Dipartimento di Strutture, Geotecnica e Geologia Applicata, Università della Basilicata, Potenza, Italy; e-mail: marco.mucciarelli@unibas.it. motion or by secondary site effects (liquefaction, soil settlement, slope instability, etc.). As often it happens in seismology, also for microzonation each earthquake is an occasion to learn new lessons, and the Umbria-Marche seismic sequence occurred in September 1997 is no exception. In the 10 years elapsed since that event, several microzonation studies were carried out in the area. Immediately after the event, the studies were aimed to the most damaged area and to support emergency intervention and reconstruction plans. In the following years, regional and national projects were aimed to transfer the lessons learned to other towns (among the others Spoleto, Cerreto di Spoleto, Città di Castello, Gubbio, Fabriano, Cagli, Treia, Serra de'Conti, Offida, Senigallia). Hav- 
ing more time (and sometimes more resources) available, the second kind of studies were carried out performing more experimental work in situ and more detailed modelling, while the first studies used a limited amount of geophysical and geotechnical data and rely mostly upon geological maps and 1-d models.

Usually, those two kinds of microzonation studies are referred to as «simplified» and «detailed». The difference is more subtle, and leads to the question if a microzonation study can be tackled following a reductionist approach, i.e. leaving different experts taking care of a limited subject (geology, geophysics, seismology, geotechnics, structural engineering) and drawing conclusions from that.

A further need of microzonation studies is to produce something that can be transferred to codes and practitioners, and here the problem is to (quoting A. Einstein) «make things as simple as possible, but not simpler». This problem was born with modern seismology. The year 2007 marks not only the $10^{\text {th }}$ anniversary of the 1997 Umbria-Marche quake but also the $150^{\text {th }}$ anniversary of the 1857 Val d'Agri quake. After a field trip in the affected area, Robert Mallet wrote its book «First principles of observational seismology». The problem of which geological and morphological situations could influence the observed damage distribution was already tackled by previous studies, but Mallet is the first to understand the problem of biased distribution of experimental evidence. He wrote: «Much pain has been devoted by earthquake describers (Hamilton, Dolomieu, Spallanzani, and others) to the question whether towns situated upon the plain on loose material, or those on the solid rocks on hill tops, suffered most; and their discussions evince much obscurity of thought, having no guiding principle.... Were the whole of the facts ... discussed with regard to this question, it would be found, that more places were destroyed upon the rock, than upon loose clay or other such foundations, and more upon hills than upon plains; but this would not conduct us to the whole truth, because in all South Italy, there are a great many more places upon rock and upon hills, than upon clays and low plains».

\section{Review of simplified microzonation studies}

A work that takes into account the problem outlined by Mallet was published by Tertulliani (2000). This paper examines all the localities affected by the first two shock of the UmbriaMarche sequence with a damage reaching VI-VII degree in the European Macroseismic Scale. A simplified geo-morphological scheme is then proposed, distinguishing town located either a) on alluvium near the basin edge; (b) on fan debris; (c) on debris-alluvium transition; (d-e) on bedrock debris transition; (f) on bedrock-alluvium transition; ( $\mathrm{g}$ ) on bedrock; (h) on alluvium far from the basin edge. The conclusion is that «heavy damage occurred in hamlets settled on alluvial deposits near to the edge of the basin, with a border fault to mark the bedrock limit» while «the severity gradually decreases as we move to villages settled on debris and on a bedrock-debris transition. The lowest intensity is found on bedrock sites and on the inner part of the basin». Stratigraphy appears thus to be a governing factor more important than morphology.

The most extensive microzonation study aimed to emergency purposes was performed by Pergalani et al. (1999). In this work «a team of surveyors were trained to collect field information such as geologic and geomorphologic features and, where possible, pre-existing geotechnic or geophysic information. Information was collected and analysed with the aid of dynamic codes to calculate the possible local site effects». Using 60 villages as a training set, the authors produced a generalization of the stratigraphic and morphologic situations, synthesized in a table grouping morphology types (valley, ridges or slopes) and lithologic units and thickness, and finally assigning to each zone a frequency-independent amplification factor according with the provision of the then enforced seismic code. The conclusion was that «the procedure ... prove to be a suitable tools for site effects assessment in post-event situation when time and budget constraint are present; in fact about 1000 sites have been surveyed and an estimate of the possible amplification established in less than six months. The average cost was also relatively small: about US\$1500 for each site». Some years later, Marzorati et al. (2003) performed a work aimed to 
«evaluating the accuracy of that methodology, following a completely different approach. The actual damages, detected by an aerial photo interpretation, are compared to the theoretical damages estimated through empirical curves». The conclusions are particularly interesting from the point of view of the knowledge transfer to practitioners: «most of the errors detected in the comparison are... not ascribed to the methodology, but are simply due to the incorrect application of the reference table proposed for the zonation, or to the inaccurate geologic and geomorphologic surveys. Those erroneous evaluations could be justified only if considering that the microzoning had to be carried out so rapidly that several surveyors not adequately trained were employed... Other inaccuracies revealed new geomorphological and geological settings that have to be included in the reference table, like the saddle-like morphology and the surface faulting».

Among the single-technique approaches to microzonation, two methodologies were tested on large data sets for the first time in Italy.

Goretti and Dolce (2002) used an objective methodology to identify damage enhancements from observed data, called Normalised Damage Index: «the distribution of the seismic intensity that actually affected buildings is obtained by means of well-assessed vulnerability functions, together with a Bayesian approach, and taking into account uncertainties in building type and building damage».

Mucciarelli and Monachesi (1998) performed a series of measurements using the HVSR technique (Nakamura, 1989) following the suggestion about how to collect and process data provided by Mucciarelli (1998). The measurements were taken in 12 sites arranged in couple of places where a strong difference in intensity occurred within a short distance. Then a correlation was sought between the intensity variation and the amplification ratio in different band of frequency. The result was that the higher correlation occurred in the range $1-2 \mathrm{~Hz}$.

\section{Review of detailed microzonation studies}

From 1997 to 2007, several studies for microzonation were performed in towns located in the Umbria and Marche regions. The main studies are listed in the following: Nocera Umbra (Cattaneo and Marcellini, 2000), Fabriano (Marcellini and Tiberi, 2000), Cagli, Treia, Serra de'Conti, Offida (Mucciarelli and Tiberi, 2004), Città di Castello (Bordoni et al. 2003), Cerreto di Spoleto (Martino et al., 2006) Senigallia (Mucciarelli and Tiberi, 2007), Spoleto (Vuan et al., 2007), Gubbio (Fiorini et al., 2007). These works mixed in a different degree geological, geophysical and geotechnical data, but are all united by a common feature: the use of recorded earthquakes.

The main results of these works concern three points: 1) the importance of 2-d effects in sedimentary basins; 2) mixed experimental and numerical evidence of strong morphologic effects; 3) the importance of soil-building resonance for damage enhancement.

\subsection{2-d effects}

The strongest amplification recorded for the Umbria-Marche earthquake occurred in the Gubbio basin (Castro et al., 2004). In general, alluvial plains were affected by high amplification, as demonstrated also for Città di Castello basin (Bordoni et al., 2003) and Colfiorito basin (Di Giulio et al., 2003). The importance of this kind of effects is well known to seismologist and engineers, but nothing has been done so far for their inclusion in the seismic codes, notwithstanding proposals aimed to this goal (Chavez-Garcia and Faccioli, 2000).

\subsection{Morphologic effects}

There has been mixed evidence about the role of morphology in amplifying recorded seismic ground motion in the Umbria-Marche area. Laurenzano et al. (2008) noted no amplification on the Treia ridge but a strong amplification in the underlying valley. Marsan et al. (2004) analysing the data from two arrays, «observed a large amplification in the basin border of Cesi site, in opposite small amplification due to topografic effect in Sellano site». Martino et 
al. (2006) studied the sharp ridge of Cerreto di Spoleto. They deployed a seismological array «in order to highlight possible topographic amplification effects all along the ridge; the findings, however, at least with the low energy level of the recorded ground motion, do not point out any topographic amplification» and after the study of the rock mass fracturation, they concluded that «rock sites can show seismic amplification effects other than the topographic one. In particular, the seismic response in a rock mass ridge can be affected by rock mass jointing: adjacent rock masses with significantly different jointing and specific geometries seem to favour trapped wave amplification, if persistence along depth of these characteristics occurs». The amplification due to waves trapped inside a fault zone was already observed and modelled by Rovelli et al. (2002) for Nocera Umbra. The Italian seismic code disregarded the problem of amplification at rock sites, abolishing the hard-rock class of the NEHRP classification scheme (Vs30>1500 m/s). On the contrary, the new provisions introduce topographic amplification for all the slopes with more than $15^{\circ}$ inclination.

\subsection{Soil-building resonance}

During the Umbria-Marche sequence, the enhancement of damage due to soil-building resonance was studied for first time in Italy with digital instrumentation.

Some of the most peculiar damage patterns observed were ascribed to soil-building resonance, as for the case of damage to reinforced concrete buildings in a limited area of Fabriano (Marcellini and Tiberi, 2000; Mucciarelli et al., 2001;) or the damage to retrofitted buildings in the historical centre of Sellano (Mucciarelli et $a l ., 2001$; Nunziata and Natale, 2004). The case of these last two works is interesting because they reach similar conclusions starting from independent dataset and models. Mucciarelli et al. (2001) performed empirical measurement of ambient vibration on both soil and buildings, concluding that «the amplifcation is mainly due to a 2-d hill-top effect, with variability due to anthropic fills. It is clear that the damage is greater for buildings whose frequency approaches the site transfer function». Nunziata and Natale (2004) aimed to reproduce accelerometric recording using numerical modelling and concluded that «taking into account the building typology of 2-3 floors, the high damage level might be attributed not only to the degraded conditions of the brick houses but also to $2 \mathrm{D}$ amplification effects, as the frequencies of the maximum peaks of the spectral amplification correspond to the eigenfrequencies of the buildings». Notwithstanding this evidence, no mention is made in the Italian code about the possibility of taking into account the frequency of soil and building for the existing structures to be retrofitted.

\section{Discussion}

Other events in Italy (like the 2002 Molise earthquake) were tackled using methodologies that were first applied after the UmbriaMarche sequence. The data collected during Umbria-Marche microzonation campaigns were a valuable source of information for further studies.

For example, shear waves velocity estimates contributed with those performed in other regions to verify the reliability of Vs30 as a proxy of seismic amplification (Mucciarelli and Gallipoli, 2006; Gallipoli and Mucciarelli, 2009). These studies concluded that $« V s 30 \ldots$ is not a good proxy of observed amplification effects in about one third of the sites. The reason why in Italy Vs30 does not provide satisfactory estimates is linked to peculiar geological settings that are widespread in the country. Vs30 seems to work fine only if a site has a strictly monotonic velocity profile increasing with depth and a strong impedance contrast in the first dozen meters».

The data from Umbria-Marche helped also to investigate the effect of selective under-sampling mentioned in the introduction (Mucciarelli and Gallipoli, 2004). From 1997 to 2004 years, our group conducted two kinds of HVSR campaigns: microzonation studies and post earthquake surveys. The aim was different: in the first case, we sampled all the municipalities 
or sites within the study area without a priori selection; in the second case, we performed measurements aimed at investigating possible resonance phenomena between the fundamental frequency of the soil and the one of damaged buildings. Thus in this second case we performed a selection driven by the observed damage. The existence of hidden selection criteria in a sample may introduce unwanted bias in the outcome. We performed all the measurement using the same instrumentation and processing technique. With a database of 540 HVRS measurements, we compared three samples: 407 measurements from microzonation studies in different Italian regions (Umbria, Marche, Basilicata, Molise), 79 from post- earthquake surveys (Umbria-Marche, Slovenia, CalabroLucano, Izmit) and 54 from our latest postearthquake survey (Molise). In this last case, we performed measurements not only at the most damaged sites, but also more uniformly in the investigated area (Gallipoli et al., 2004). The variable we considered for our statistics is the highest HVSR value in the frequency range $0.5-10 \mathrm{~Hz}$. It is clear from fig. 1 that the data from microzonation studies and post-quake survey have similar distributions but very different parametrisation. The main result from fig. 1 is the probability of observing high HVSR values at randomly sampled sites. The data sampled during microzonation studies have a lower probability than the ones resulting from postquake studies. This means that there are few sites with strong local amplification, and they are those that claim for attention when the damage is driving our researches. The distribution observed after the Molise 2002 event shows that a study conducted after an earthquake yield the same distribution of earthquake-independent studies, provided that the sampled location are not pre-selected but the whole area is investigated.

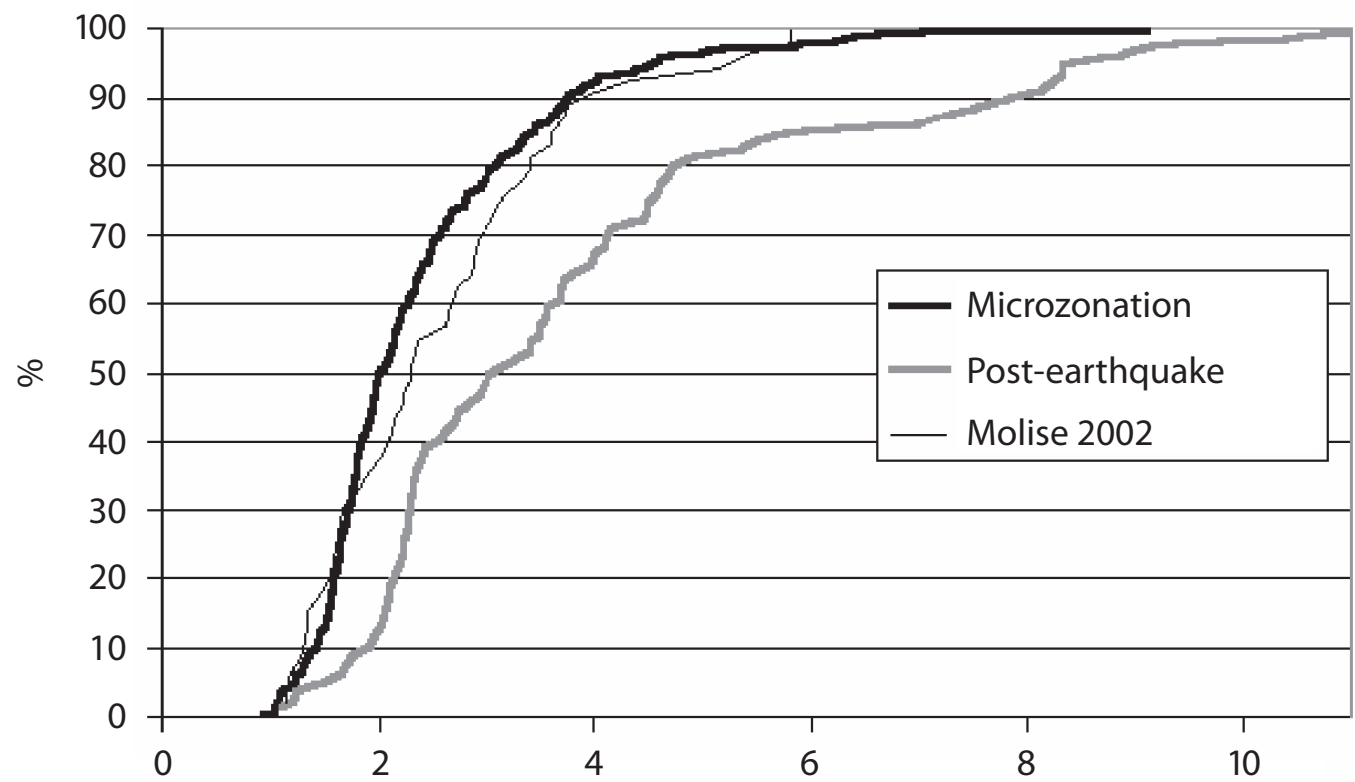

\section{$0.5 \mathrm{~Hz}<$ Max HVSR $<10 \mathrm{~Hz}$}

Fig. 1. Comparison between the empirical cumulative distribution functions of different sets of HVSRs, as a function of the largest value observed in the frequency range $0.5-10 \mathrm{~Hz}$. See text for details. 


\section{Conclusions}

The Umbria-Marche sequence provided several valuable lessons about microzonation studies. These can be summarised in the following:

1. no simple method is safe enough if the practitioners are not well-trained to use it;

2. the strongest amplifications recorded for the Umbria-Marche earthquake were due to 2-d basin effects;

3. topographic amplification, if and where present, is a second-order problem with respect to impedance contrast amplification;

4. the most peculiar damage patterns observed were due to soil-building resonance;

5 . Vs30 is not a good proxy of observed amplification effects in about one third of the cases.

Very little of this information was taken into account for the formulation of the Italian seismic code.

A leitmotiv often repeated is that the codes must be simple or the practitioners could have problems in applying them. One may wonder if any of us would oppose the diffusion of medical ultrasonography or computed tomography scans on the basis that old-fashioned doctors are familiar just with their wooden stethoscopes. A wrong diagnosis is never good, not only if the illness is worst than assumed, but also in case of over-conservatism, causing unnecessary expense and routing limited resources where they are not needed.

Ten years after the Umbria-Marche quake, but also ten years after the introduction of the NEHRP-FEMA provisions, the world outside Italy has treasured the experiences gathered in the meanwhile.

- The relationship between acclivity and amplification has been revised by Wald and Allen (2007) who propose using the topographic map as a first order support for determining amplification via Vs30 since «topographic variations should be an indicator of near-surface geomorphology and lithology ... with steep mountains indicating rock, nearly flat basins indicating soil, and a transition between the end members on intermediate slopes».

- The presence of amplification in sites with
$1500<\mathrm{Vs} 30<800$ has been repeatedly described (see, e.g., Sokolov et al., 2007).

-The fact that soil non-linear behaviour is not always a guarantee of lesser amplification was studied by Bonilla et al. (2005), that showed how the hysteretic and dilatant behaviour of cohesionless soils «increases the duration of the strong shaking and in some circumstances produces the maximum acceleration».

- The need to overcome the classification based on velocity profiles only has been invoked by studies that propose to include soil fundamental period (Rodriguez-Marek et al. 2001, Pitilakis et al., 2006) as well as 2-d effects (Chavez-Garcia and Faccioli, 2000).

- The importance of soil building resonance in microzonation studies was shown by Navarro et al. (2004) and recently discussed in an international workshop (Cassidy et al., 2008) whose conclusions were that «There is general agreement that soil-building resonance can be a cause of damage enhancement. There are suggestions that peculiar damage patterns (e.g. the collapse of a single building in a set of identical ones) could be due to city-soil interaction. There is the need to better quantify the occurrence of resonance taking into account the time-varying, non-linear behaviour of soil and building subjected to strong ground motion».

There is no clearcut conclusion from this list of questions and problems, but the impression is that microzonation studies must be interdisciplinary and no conclusion should be drawn using (outdated) models based on a single technique. To evaluate the virtues of an holistic approach we can find again inspiration in the work of Robert Mallet. He was an engineer, stated the rules for seismology and wrote beautiful pages about local geology and site effects: disciplinary barriers and fences were introduced much later on, and we can ask ourselves if we had a real payback from that.

\section{REFERENCES}

Bonilla, L.F, R.J. Archuleta and D. Lavallée (2005): Hysteretic and Dilatant Behavior of Cohesionless Soils and Their Effects on Nonlinear Site Response: Field 
Data Observations and Modeling, Bull. Seism. Soc. Am., 95, 2373-2395.

Bordoni, P., G. Cultrera, L. Margheriti, P. Augliera, G. Caielli, M. Cattaneo, R. De Franco, A. MicheLINI and D. SPAllarossa (2003): A microseismic study in a low seismicity area: the 2001 site-response experiment in the Città di Castello basin (Italy), Annals of Geophysics, 46 (6), 1345-1360.

Cattaneo, M. and A. MARCELlini (Editors) (2000): Terremoto dell'Umbria-Marche: Microzonazione sismica di Nocera Umbra e Sellano, (CNR-GNDT - Roma, 2000, pp 228. + CD-ROM, ISBN 88-900449-7-5).

Chavez-Garcia, F.J. and E. Faccioli (2000): Complex site effects and building codes: making the leap, Journal of Seismology, 4, 23-40.

Di Giulio, G., A. Rovelli, F. Cara, R.M. Azzara, F. MARRA, R. BASILI and A. CASERTA (2003): Long-duration asynchronous ground motions in the Colfiorito plain, central Italy, observed on a two-dimensional dense array, J. Geophys. Res., 108 (B10), 2486, doi: 10.1029/2002JB002367.

Fiorini, E., F. Pacor, D. Bindi, A. Rovelli, F. CARA, G.. Di Giulio, G.. Milana, G.. Monachesi, D. Nieto, G. Bohm, D. Albarello, V. D’Amico, M. Picozzi, M. Mucciarelli, G. Scarascia Mugnozza, S. Rivellino, M. Menichetti, S. Parolai, S. Richwalski and I. OrPSAL (2007): Geological model of the Gubbio basin (Italy) for the characterisation of local seismic response, Report for the INGV-DPC project $S 2.3 .6$, (last download at http://esse3.mi.ingv.it/deliverables/Deliverables_S3_D21.pdf).

Gallipoli, M.R., M. Mucciarelli, M. Tropeano, S. GalLICCHIO and C. LIZZA (2004): HVSR measurements in the area damaged by the 2002 Molise, Italy earthquake, Earthq. Spectra, 20, S81-S94.

Gallipoli, M.R. and M. Mucciarelli (2009): Comparison of site classification from Vs30, Vs10 and HVSR in Italy, Bull. Seism. Soc. Am., 99 (1), doi: 10.1785/01200800083.

Goretti, A. and M. Dolce (2002): Site effects evaluation from surveyed typological and damage data, Proc. $12^{\text {th }}$ European Conference on Earthquake Engineering, (CD-ROM edition), pp. 10.

Laurenzano, G., E. Priolo and E. Tondi (2008): 2-D numerical simulations of earthquake ground motion: examples from the Marche Region, Italy, in press on Journal of Seismology.

Marcellini, A. and P. Tiberi (Editors) (2000): La microzonazione sismica di Fabriano, (Biemmegraf, Piediripa di Macerata), p. $350+$ CD-ROM.

Marsan, P., G. Milana, A. Pugliese and T. SAnò (2004): Local amplification effects recorded by a local strong motion network during the 1997 Umbria-Marche earthquake, $13^{\text {th }}$ World Conference on Earthquake Engineering Vancouver, (CD-ROM, Paper No. 1046).

Marzorati, S., L. Luzi, V. Petrini, F. Meroni and F. PerGALANI (2003): Detection of local site effects through the estimation of building damages, Soil Dyn. and Earthq. Engin., 23, 497-511.

Martino, S., A. Minutolo, A. Paciello, A. Rovelli, G. Scarascia Mugnozza and V. Verrubbi (2006): Evidence of Amplification Effects in Fault Zone Related to Rock Mass Jointing, Nat. Haz., 39, 419-449.

MucCIARELli, M. (1998): Reliability and applicability range of the Nakamura's technique using microtremors. An experimental approach, Journ. Earthq. Eng., 2, 625-638.

Mucciarelli, M. and G. Monachesi (1998): A quick survey of local amplifications and their correlation with damage observed during the Umbro-Marchesan earthquake of September 26, 1997, Journ. Earthq. Eng., 2, $1-13$.

Mucciarelli, M., P. Contri, G. Monachesi, G. Calvano and M.R. GALlipoli, (2001): An empirical method to assess the seismic vulnerability of existing buildings using the HVSR technique, PAGEOPH, 158, 26352647.

Mucciarelli, M., M. Herak and J. CAssidy (Editors) (2008): Inreasing Seismic Safety by Combining Engineering Technologies and Seismological Data, (Springer, Dordrechts, The Netherlands, ISBN 978-14020-9194-0), pp. 382.

Mucciarelli, M. and P. Tiberi (Editors) (2004): Microzonazione sismica di Cagli, Offida, Serra de'. Conti, Treia. Regione Marche, (GNDT-INGV,), pp. 71+ CD-ROM.

Mucciarelli M. and M.R. Gallipoli (2004): The HVSR technique from microtremor to strong motion: empirical and statistical considerations; $13^{\text {th }}$ World Conference on Earthquake Engineering Vancouver, (CDROM, Paper No. 45).

Mucciarelli, M. and M.R. Gallipoli, (2006): Comparison between Vs30 and other estimates of site amplification in Italy, Proc. $1^{\text {st }}$ European Conference on Earthquake Engineering and Seismology, CD-ROM edition, paper 270 .

Mucciarelli, M. and P. Tiberi (Editors) (2007): Microzonazione sismica di Senigallia, (Tecnoprint Ancona), pp. $420+2$ CD-ROM.

Navarro, M., F. Vidal, M. Feriche, T. EnOMOto F.J. SANCHEZ and I. MATSUDA (2004): Expected ground-r.c building structures resonance phenomena in Granada city (Southern Spain), $13^{\text {th }}$ World Conference on Earthquake Engineering, (Vancouver, B.C., Canada August 1-6, Paper No. 3308).

NAKAmura, Y. (1989): A method for dynamic characteristics estimation of subsurface using microtremor on the ground surface, Q. Rept. Rail. Tech. Res. Inst., 30 (1), 25-33.

NunZiatA, C. and M. NATAle. (2004): Spectral Amplification Effects at Sellano, Central Italy, for the 1997-98 Umbria Seismic Sequence; Natural Hazards, 33, 365378 .

Pergalani F., R. Romeo, L. Luzi, V. Petrini, A. Pugliese and T. SANÒ (1999): Seismic microzoning of the area struck by Umbria-Marche (Central Italy) $\mathrm{M}_{\mathrm{s}} 5.9$ earthquake of 26 September 1997, Soil Dyn. and Earthq. Engin., 18, 279-296.

Pitilakis, K., C. GazePis and A. Anastasiadis (2006): Design response spectra and soil classification for seismic code provisions, Proc. of the Workshop on Geotechnical Evaluation and Application of the Seismic Eurocode EC8, (Athens), pp. 31-46.

Rodriguez-MareK, A., J.D. Bray and N.A. Abrahamson (2001): An Empirical Geotechnical Seismic Site Response Procedure, Earthquake Spectra, 17, 65- 87.

Rovelli, A., A. Caserta, F. Marra and V. Ruggiero (2002): Can seismic waves be trapped inside an inac- 
tive fault zone? The case study of Nocera Umbra, Central Italy. Bull. Seism. Soc. Am., 92, 2217-2232.

Sokolov, V., Y., LohB C-H. and W.-Y. JeAn (2007): Application of horizontal-to-vertical (H/V) Fourier spectral ratio for analysis of site effect on rock (NEHRP-class B) sites in Taiwan, Soil Dyn. Earthq. Engin., 27, 314323.

Tertulliani A. (2000): Qualitative effects of local geology on damage pattern, Bull. Seism. Soc. Am., 90 (6), 15431548 .
Vuan A., M. Romanelli, C. Barnaba, A. Restivo, L. LoVISA, E. Priolo and G. Rossi (2007): Relazione Scientifica Finale. Convenzione tra Comune di Spoleto e OGS per lo studio di microzonazione del centro storico della Città di Spoleto, (Rel. OGS 2007/53-CRS/12, last download at http://www.ogs.trieste.it/Show/UploadFile/file.aspx ?IdFile=105\&IdUniversity=2).

WALD D.J. and T.I. Allen (2007): Topographic slope as a proxy for seismic site conditions and Amplification; Bull. Seism. Soc. Am., 97, 1379-1395. 